\title{
Occupational stress among operating room nurses of hospitals affiliated to Kerman universities of medical sciences, Iran (2016): A cross-sectional study
}

\author{
Soltanmoradi Y, MSc Student ${ }^{1}$, Ansari A, MSc ${ }^{2}$, Heidari Sh, $\mathrm{PhD}^{3^{*}}$ \\ 1- MSc Student of Medical Surgical Nursing, School of Nursing and Midwifery, Student Research Committee, Rafsanjan \\ University of Medical Sciences, Rafsanjan, Iran. 2- Academic Member, Dept. of Psychiatric \& Mental Health Nursing, \\ School of Nursing and Midwifery, Social Determinants of Health Research Center, Rafsanjan University of Medical \\ Sciences, Rafsanjan, Iran. 3- Assistant Prof., Dept. of Fundamental Nursing, School of Nursing and Midwifery, Geriatric \\ Care Research Center, Rafsanjan University of Medical Sciences, Rafsanjan, Iran.
}

Abstract

Received: June 2017, Accepted: October 2017

Background: Nurses' working environments, especially operating rooms are stressful environments due to their undesirable factors and conditions. The present study was conducted to determine sources of occupational stress among operating room nurses of hospitals affiliated to universities of medical sciences in Kerman, Iran.

Materials and Methods: This cross-sectional study was carried out in the operating rooms of hospitals affiliated to universities of medical sciences, in Kerman. The sample population consisted of 250 operating room nurses with at least 1 year of work experience. The subjects were selected using randomized cluster sampling. Data were collected using a socio-demographic data form and the Expanded Nursing Stress Scale (ENSS). The collected data were analyzed using independent t-test, Pearson correlation, and ANOVA in SPSS software.

Results: Operating room nurses rated situations of the "death and dying" subscale as the most stressful, whereas situations of "discrimination" were described as less stressful. Uncertainty concerning treatment was significantly affected by gender; women had higher scores in this subscale $(\mathrm{P}=0.019)$. Moreover, general operating room nurses (vs. specialized) had significantly higher mean scores regarding the perception of the stressfulness of "inadequate preparation", "conflict with physicians", and "discrimination" subscales $(\mathrm{P}<0.50)$.

Conclusions: The situations of the death and dying subscale were the most important stressors from the viewpoint of operating room nurses. Due to nurses' constant observation of patients' pain and suffering, preparing them for coping with such stressors is necessary through education and organizational/familial supports.

Keywords: Occupational Stress, Operating Room, Nurse, Iran

\section{Introduction}

Today, individuals' concern about work, organizations' expectations of employees, and the advancement of technology have caused individuals to experience various stresses $(1$, 2). Hans Selye has defined stress as "the nonspecific response of the body to any demand for change", which may be a threat, conflict, or any kind of pleasant and unpleasant change that requires body adaptation (3). Occupation is one of the main causes of stress in life. On average, one million people per day do not attend work due to occupational stress disorders. Furthermore, $4 \%$ of working hours is lost due to stress-related absence. Individuals experience greater stress in occupations which involve human contact (4). The National Institute for Occupational Safety and Health (NIOSH) defines occupational stress as a harmful physical and mental

* Corresponding author: Shahin Heidari, Dept. of Fundamental Nursing, School of Nursing and Midwifery, Geriatric Care Research Center, Rafsanjan University of Medical Sciences, Rafsanjan, Iran.

E-mail: kermanshah3252@yahoo.com 
response, the incidence of which is related to lack of coordination of occupational requirements with abilities, support sources, and requirements of the employed individual (5).

Hospital occupations involve a high degree of occupational stress (6). Health care providers, especially nurses, experience a high level of stress, because they are responsible for the well-being of humans (7). The operating room environment is considered as a stressful environment due to undesirable environmental factors and conditions like noise, light, radiation, heat, humidity, high workload, low number of staff, and heavy responsibilities (8). The operation room is a place with high occupational stress and low occupational satisfaction. Stimuli such as the need for quick and immediate action, medical disputes, uncertain work shifts, handling of intricate equipment, and the need for mastery of complex surgical techniques impose a high degree of pressure on nursing staff $(9,10)$. As a result, nearly half of them have moderate to severe stress (11). They spend more time, even occasionally, all their time in a closed and sterilized environment, which in turn can be stressful (12). This stress affects the performance of the operating room staff (13). One of the most important factors effective on the amount of stress experienced by the operating room staff is the type of hospital and the number of patients admitted to each hospital (14).

Different individuals display different behaviors in response to stresses. Coping strategies are behavioral and cognitive efforts to deal with stressful behaviors and to meet internal and external needs (15). People who use coping techniques in an appropriate way can reach a higher level of quality of life (QOL) (16). Identifying the sources of stress and coping styles of nurses plays an important role in increasing the ability to cope with stressors and reducing or eliminating these factors (17). Nurses can examine their stress levels and continue their careers effectively, creatively, and with satisfaction through the early detection of stress symptoms and the use of ways to reduce them (18).

Sources of occupational stress and coping strategies of nurses in the operating rooms of Kerman Province, Iran, have not been studied previously. Moreover, this variable is influenced by cultural, racial, religious, and educational characteristics (19). Therefore, the present study was conducted with the aim to determine the sources of occupational stress among nursing staff in operating rooms of hospitals affiliated to universities of medical sciences of Kerman Province in 2016.

\section{Material and Methods}

In this cross-sectional study, which was conducted in 2016, the research environment was the operating rooms of the hospitals affiliated to universities of medical sciences of Kerman Province, and the research community consisted of operating room nursing staff. The sample size in this study was determined using the formula for estimation of ratio. According to the results of a previous study (20), the ratio of nurses with occupational stress was $40 \%$ (P $=0.40$ ), the confidence coefficient was 0.95 , and $d$ was equal to 0.065 . Using equation (1), the sample size was calculated as 219 individuals.

$$
n=\frac{Z_{1-\frac{\alpha}{2}}^{2} \times P \times(1-P)}{d^{2}} \quad \text { (Equation 1) }
$$

Considering the sampling method used (cluster sampling), 20\% was added to the sample size, and thus, 250 people participated in the study. In order to achieve the above sample size, the researchers used cluster sampling. In this study, clusters were hospitals with operating rooms throughout the province. The number of clusters was 15 hospitals and the number of individuals occupied in these 15 clusters was 620. Considering that the required sample size was approximately $40 \%$ of the target population, $40 \%$ of the clusters (6 clusters) were randomly selected using lottery method. The chances of the selection of clusters in the lottery were the same. Sampling in the clusters 
was performed using convenience sampling based on the inclusion criteria of the research. The clusters included 3 operating rooms in Kerman City, 2 operating rooms in Jiroft City, 2 operating rooms in Sirjan City, 3 operating rooms in Rafsanjan City, and 1 operating room in Bam City. The study inclusion criteria included a degree in paramedicine, an associate, bachelor's, or master's degree in nursing, anesthesia, or operating room, at least 1 year of work experience in the operating room, employment in the operating room during the research period, and satisfaction and willingness to participate in the research. The subjects also had no neurological and psychiatric disorders (based on medical records), and did not use drugs that affect human mood (like benzodiazepines, antidepressants, and antipsychotics). The exclusion criteria consisted of a major stressful incident, such as the death of loved ones during the research period, and the diagnosis of a serious illness.

The data collection tools included a sociodemographic characteristics form (age, sex, marital status, educational level, income level, and etc.) and the Expanded Nursing Stress Scale (ENSS), which was completed as selfreport. The ENSS (57 questions) was reviewed by French et al. in 2000 and includes 57 potentially stressful situations which have been classified in 9 subscales. Nurses were asked to express their stress levels when confronted with the mentioned situations. The subscales included potentially stressful situations related to death and dying (7 questions), conflict with physicians (5 questions), inadequate preparation (3 questions), uncertainty about treatment (9 questions), problems with colleagues (6 questions), problems with supervisors (7 questions), workload (9 questions), patients and their families (8 questions), and discrimination (3 questions). The subscales of death and dying, inadequate preparation, and uncertainty about treatment were named the psychological environment, the workload factor was named the physical environment, and the remaining subscales were called the social environment (21). The questionnaire was scored based on 5-point Likert scale ranging from 0 to 4 . Scores 0 to 4 , respectively, belonged to the options "I have not faced this situation", "I do not have any stress", "I am sometimes stressful", "I often have stress", "I have extreme stress". Therefore, a score between 0 and 4 was considered for each question and the average of each question was compared with the rest of the questions. No definite cut-off point indicating whether a person is stressed has been defined in previous studies. Nevertheless, higher scores represent more stress (22). This questionnaire has been used in Iran, and Ghanei et al. have reported its reliability using Cronbach's alpha coefficient as 0.92 (23).

After obtaining initial permissions, receiving the ethics code, and choosing the desired clusters, the researchers participated in various work shifts in the research environment. In order to obtain the subjects' informed consent for participation in the study, the necessary explanations were given about the research objectives and they were assured that their information would remain confidential and would be used only in the present study. Then, the researchers distributed the questionnaires and collected them after completion on the same day.

Data were collected, and then, analyzed in SPSS software (version 18, SPSS Inc., Chicago, IL, USA). The normal distribution of data was confirmed using KolmogorovSmirnov test $(P=0.273)$. The Pearson correlation coefficient was used to investigate the relationship between variables, including the relationship between different subscales of the questionnaire and also the relationship of demographic characteristics with stress score in different subscales. Furthermore, independent t-test was used to compare mean scores. ANOVA was used to compare more than two groups and the significance level in all tests was less than 0.05 .

Ethical considerations: This study was approved by the Ethics Committee of 
Rafsanjan University of Medical Sciences, Iran, with the code of ethics IR.RUMS.REC.1395.25. The researchers explained the objectives of the study to the participants and the questionnaires included no signs of identification. In addition, the participants were assured that their information would remain confidential and how they answered questions would have no effect on their job process.

\section{Results}

The research sample included 250 nursing staff of operating rooms of hospitals affiliated to universities of medical sciences in Kerman Province. The participants consisted of 85 individuals from 3 operating rooms in Kerman City (Afzalipour, Bahonar, and Shafa hospitals), 50 individuals from Rafsanjan City (Ali ibn Abi Talib and Moradi hospitals, and Niknafs maternity hospital), 40 individuals from Jiroft City (Imam Khomeini Hospital and Kashani Hospital), 45 individuals from the City of Bam (Pasteur Hospital), and 30 individuals from Sirjan City (Imam Reza Hospital). The research findings showed that the mean age of the subjects was $33.10 \pm 7.39$ years and most of them (74.0\%) were women. Most of the participants (69.2\%) had a bachelor's degree. In terms of the type of operation room, $72.4 \%$ were working in the general operating room, and the rest in specialized operating rooms. Most of the subjects (74.0\%) were married and were officially employed in terms of employment status. The average work experience of participants was $9.68 \pm 4.22$ years. In terms of job category, most of them were anesthesiologists. Other demographic characteristics of the subjects are listed in table 1.

Table 1: Demographic characteristics of the nursing staff of operating rooms in hospitals affiliated to universities of medical sciences in Kerman, Iran, in 2016

\begin{tabular}{|c|c|c|c|}
\hline \multicolumn{2}{|c|}{ Demographic characteristics } & \multirow{2}{*}{$\frac{\text { Number }}{187}$} & \multirow{2}{*}{$\frac{\text { Percentage }}{74.8}$} \\
\hline Condon & Woman & & \\
\hline Gender & Man & 63 & 25.2 \\
\hline \multirow{4}{*}{ Education } & Diploma & 19 & 7.6 \\
\hline & Associate degree & 47 & 18.8 \\
\hline & Bachelor's degree & 173 & 69.2 \\
\hline & Master's degree & 11 & 4.4 \\
\hline \multirow{4}{*}{$\begin{array}{l}\text { Employment } \\
\text { status }\end{array}$} & Human resources plan & 43 & 17.2 \\
\hline & Contractual & 40 & 16 \\
\hline & Compensation force & 53 & 21 \\
\hline & Official & 114 & 45.6 \\
\hline \multirow{2}{*}{$\begin{array}{c}\text { Type of operation } \\
\text { room }\end{array}$} & General & 181 & 72.4 \\
\hline & Specialized & 69 & 27.6 \\
\hline \multirow{3}{*}{ Marital status } & Married & 187 & 74.8 \\
\hline & Single & 60 & 24 \\
\hline & Divorced & 3 & 1.2 \\
\hline \multirow{4}{*}{ Work shift } & Morning & 21 & 8.4 \\
\hline & Afternoon & 6 & 2.4 \\
\hline & Night & 3 & 1.2 \\
\hline & Circulating shifts & 220 & 88 \\
\hline
\end{tabular}

Data analysis showed that, from the participants' viewpoints, the situations of death and dying and uncertainty about treatment with means and standard deviations of $2.33 \pm 0.79$ and $2.32 \pm 0.77$, respectively, were the most important sources of occupational stress among nurses. However, situations of the subscales of discrimination and problems with colleagues with the mean and standard deviations of $1.25 \pm 0.93$ and 
$1.54 \pm 0.76$, respectively, were of less importance. The mean and standard deviation of various subscales of occupational stress sources are presented in table 2. Analysis of all 57 potentially stressful situations among nurses showed that being in the situations of "performing painful measures for patients" and "observing the patient's pain", both from the subscale of death and dying, caused the highest degree of stress among nurses. However, the situation of "being sexually abused" in the subscale of discrimination was placed in the lowest rank among the mentioned situations by nurses. The mean and standard deviation of sources of occupational stress among nurses in different subscales are presented in table 2 .

Table 2: Mean and standard deviation of sources of occupational stress among nurses of operating rooms in hospitals affiliated to universities of medical sciences in Kerman, Iran, in different subscales in 2016

\begin{tabular}{ccccc}
\hline $\begin{array}{c}\text { Potential stressful situations in } \\
\text { different subscales }\end{array}$ & $\begin{array}{c}\text { Mean score of questions } \\
\text { (ranging from 0-4) }\end{array}$ & Minimum & Maximum & $\begin{array}{c}\text { Standard } \\
\text { deviation }\end{array}$ \\
\hline Death and dying & 2.33 & 0 & 4 & 0.79 \\
\hline Conflict with physicians & 2.11 & 0 & 4 & 0.89 \\
\hline Inadequate emotional reparation & 1.76 & 0 & 3.67 & 0.92 \\
\hline Problems with colleagues & 1.54 & 0 & 4 & 0.76 \\
\hline Problems with head nurse & 2.19 & 0 & 4 & .93 \\
\hline Work load & 1.95 & 0 & 4 & .74 \\
\hline Uncertainty about treatment & 2.32 & 0 & 3.89 & .77 \\
\hline Patients and their families & 1.82 & 0 & 3.63 & .79 \\
\hline Discrimination & 1.25 & 0 & 4 & .31
\end{tabular}

Investigation of the relationship between demographic characteristics and sources of occupational stress in different subscales showed that the mean stress score among women in the subscale of uncertainty about treatment was significantly higher $(\mathrm{t}=-2.36, \mathrm{P}$ $=0.019)$. Furthermore, independent $t$-test showed that there was a significant relationship between the type of operation room and the mean stress score in the subscales of inadequate mental preparation $(\mathrm{t}$ $=2.28, \mathrm{P}<0.001)$, conflict with physicians $(\mathrm{t}$ $=3.07, \mathrm{P}=0.002)$, and discrimination $(\mathrm{t}=$ $3.871, \mathrm{P}=0.023)$. The mean stress score of the general operating room staff in the above subscales was higher than that of the specialized operation room staff. More information is provided in this regard in table 3.

Table 3: Mean and standard deviation of some sources of occupational stress according to the demographic characteristics of the nursing staff of the operating rooms of hospitals affiliated to universities of medical sciences in Kerman, Iran, in 2016

\begin{tabular}{|c|c|c|c|c|c|}
\hline $\begin{array}{c}\text { Subscales of occupational } \\
\text { stress sources }\end{array}$ & \multicolumn{2}{|c|}{ Name of variable } & $\begin{array}{l}\text { Mean and standard } \\
\text { deviation }(0-4)\end{array}$ & t-test & $\mathrm{P}$ \\
\hline \multirow{2}{*}{ Uncertainty about treatment } & \multirow{2}{*}{ Gender } & Woman & $3.8 \pm .97$ & \multirow{2}{*}{-2.36} & \multirow{2}{*}{.019} \\
\hline & & Man & $2.12 \pm 1.12$ & & \\
\hline \multirow{2}{*}{$\begin{array}{c}\text { Inadequate mental } \\
\text { preparation }\end{array}$} & \multirow{6}{*}{$\begin{array}{l}\text { Type of } \\
\text { operation } \\
\text { room }\end{array}$} & General & $1.91 \pm .89$ & \multirow{2}{*}{2.28} & \multirow{2}{*}{.000} \\
\hline & & Specialized & $1.43 \pm .96$ & & \\
\hline \multirow{2}{*}{ Conflict with physicians } & & General & $2.21 \pm .68$ & \multirow{2}{*}{3.07} & \multirow{2}{*}{.002} \\
\hline & & Specialized & $1.83 \pm .88$ & & \\
\hline \multirow{2}{*}{ Discrimination } & & General & $1.34 \pm .77$ & \multirow{2}{*}{3.17} & \multirow{2}{*}{.023} \\
\hline & & Specialized & $1.00 \pm .91$ & & \\
\hline
\end{tabular}


One-way ANOVA did not show a significant relationship between mean stress score in the 9 subscales and the level of education, level of income, marital status, and job category. In addition, the Pearson correlation coefficient showed no significant relationship between age and work experience, and different subscales of occupational stress sources.

\section{Discussion}

The present study was conducted with the aim to identify sources of occupational stress with the participation of 250 nurses of operating rooms in hospitals affiliated to universities of medical sciences in Kerman Province. The research sample was of maximum diversity and sampling was performed in 10 special and general operation rooms in different cities of the province. The main results of the research indicated that the situations mentioned in the area of death and dying are the most important sources of occupational stress among operating room nurses. However, situations of the subscales of discrimination and problems with colleagues were less important. A review of numerous studies on occupational stress among nurses, which have been conducted using similar tools, also suggests that nurses' confrontation with death and dying situations creates a high degree of stress for nurses. Among these, a study by Milutinović et al. can be mentioned (24). In this study, nurses working in the intensive care unit (ICU) in Serbia reported the situations mentioned in the death and dying category as the most stressful situations, while the situations related to the subscales of problems with colleagues created the least amount of stress among them (24). In an Iranian study conducted by Esfandnia et al., the most important stressor was related to situations of death and dying (25). The stressfulness of the situations of death and dying has been emphasized in other studies, like the study by Abed Saeed (26) and Qasemi (27). This finding of the present study and many similar studies can be partly due to the nature of the nursing profession. Nurses are real witnesses of death; they establish close relationships with patients and their families, support them, and are emotionally affected by these experiences (28). Nurses had negative feelings like anger, exhaustion, or frustration in the face of the death of their patient. Talking face-to-face about their negative emotions with colleagues and other people could be effective in appropriately dealing with this issue (29). In a study by Karimi et al. nurses cited a patient's death as one of the most important sources of occupational stress, and that they only received personal and familial support in dealing with this problem. These researchers concluded that nurses require organizational and familial support to cope with stress due to facing death (30).

One of the sources of stress in the subscale of death and dying was observing patients' pain and suffering and performing painful measures for them. In the study by Habrani et al., facing patients' pain and suffering was one of the most important occupational stressors for nurses (31). The constant presence of nurses at the patient's bedside and close relationship with them is one of the causes of their close contact with the sufferings of patients. Therefore, their permanent confrontation with patients' suffering and pain has been mentioned as the most important source of occupational stress among nurses. Mays et al. indicated that when patients complain of pain and sufferings or worry about their own health and that of their family, nurses are beside them and their response to the patient's pain and suffering and way of providing nursing care is of high importance (32). According to nursing standards, nurses are expected to communicate with the patient through compassionate behaviors in order to be able to respond to their suffering, as the awareness of patients' pain and suffering and attempt to reduce or eliminate it is the basis of compassionate care (33, 34). Nurses should consider their emotional responses to the deficiencies they witness every day, and learn and use coping strategies for exposure to other people's pain before experiencing signs of stress (35). It 
seems that nurses participating in this study have not used effective methods to deal with the stress caused by observing patients' pain and suffering. Training effective coping strategies to nurses and nursing students plays an important role in this context. In addition, creation of appropriate situations for nurses to express their negative emotions can reduce their emotional strain and prevent exhaustion and frustration.

The results of studies which have investigated stress due to a patient's death alone are different from the results of the present study. For example, the results of the study by Abou Hashish indicated that nurses, who had cared for more dying patients, had a more positive attitude towards dying and providing end-oflife care (36). Thus, the researchers concluded that providing care for dying patients could increase nurses' awareness of patients' feelings and emotions and strengthen nursing skills and adaptation mechanisms (36). In a study by Pyne et al. on the stress and anxiety of death in nurses, the results showed that nurses had low anxiety and stress levels in the subscale of death and dying (37). As can be seen, the results of these studies indicate that the higher exposure of nurses to the situation of patients' death has reduced their stress. This difference may be due to various factors, including the variables studied, the type of tool used, and the research environment. Nurses' viewpoints on stress resulting from care for dying patients have been investigated in these studies. To further explore this difference, more studies are needed with a similar approach.

In the present study, the mean stress score of women in the subscales of uncertainty about treatment was significantly higher than that of men, but the difference was not significant in other subscales of occupational stress. This finding is consistent with the results of the studies by Habrani et al. (31) and Mohebbifar et al. (38). Nevertheless, in the study of Asadi Fakhr et al., there was a significant relationship between gender and all subscales of stress, and stress rate was higher among the female nursing staff (12). The results of the study by Hazave'ei also indicated a higher stress level among women nurses (39). Differences in the results of studies may be due to individual differences and the research environment.

According to the results of this study, in order to effectively deal with the stress due to situations of death and dying, it is suggested that continuous and group sessions be designed for operating room nurses so that they can express their feelings and use the experiences of others to adapt to such situations.

In this study, a non-Iranian questionnaire and a quantitative method were used to determine the sources of occupational stress, which are the limitations of this research. It would be better to investigate the sources of occupational stress using qualitative research method in future studies.

\section{Conclusion}

The present study showed that nurses face several sources of stress in their work environment, among which the situations related to the subscale of death and dying were more important. Due to the continuous presence of the nurse at the patient's bedside, the permanent exposure of nurses to the pain and suffering of the patient is inevitable; hence, it is necessary to prepare nurses to deal with such stresses. Holding stress management courses for nurses and nursing students and adequate organizational and familial support can play an important role in this regard.

\section{Acknowledgements}

This article has been derived from a nursing MSc thesis. The authors wish to express their appreciation for the funding of this project by the Deputy of Research and Technology of Rafsanjan University of Medical Sciences. Moreover, they would like to thank the authorities and staff of hospitals and operating rooms in the cities of Kerman, Rafsanjan, Sirjan, Jiroft, and Bam, who collaborated with them on this research. 
Conflict of interest: None declared

\section{References}

1. Toubaei Sh, Sahraeian A. Burnout and job satisfaction of nurses working in internal, surgery, psychiatry burn and burn wards. The Horizon of Medical Sciences 2007; 12(4):405.

2. Healy CM, McKay MF. Nursing stress: the effects of coping strategies and job satisfaction in a sample of Australian nurses. J Adv Nurs 2000; 31(3):681-8.

3. Selye H. The stress of my life: a scientist's memoirs. $2^{\text {nd }}$ ed. New York, Toronto: Van Nostrand Reinhold; 1979.

4. McVicar A. Workplace stress in nursing: a literature review. J Adv Nurs 2003; 44(6):63342.

5. Sauter S, Murphy L, Colligan M, Swanson N, Hurrell J, Scharf Jr. F, et al. Stress at work. National Institute for Occupational Safety and Health. DHHS (NIOSH) Publication No. 99101. http://www.cdc.gov/niosh

6. Parvin N, Kazemian A, Hassan Poor A, Alavi A. Evaluation nurses, job stressors in Shahrekord hospitals affiliated to medical university in 2002. Modern Care Journal 2005; 2(3):31-5

7. Laal M, Aliramaie N. Nursing and coping with stress. Int J Collab Res Intern Med Public Health 2010; 2(5):168-81.

8. Tyler PA, Ellison RN. Sources of stress and psychological well-being in high-dependency nursing. J Adv Nurs 1994; 19(3):469-76.

9. Benoliel J.Q, Mccorkle R, Georgiadou F, Denton T, Spitzer A. Measurement of stress in nursing. Cancer nursing 1990; 13(4): 221-8. 10.1097/00002820-199008000-00003. https://www.researchgate.net/publication/2094 8158

10. Foxall MJ, Zimmerman L, Standley R, Bené B. A comparison of frequency and sources of nursing job stress perceived by intensive care, hospice and medical-surgical nurses. J Adv Nurs 1990; 15(5):577-84.

11. Khodaveisi M, Mohammadi N, Omidi A. Frequency of job stress in clinical nurses. Scientific Journal of Hamadan Nursing \& Midwifery Faculty 2006; 13(2):44-54.

12. Yoosefian Miandoab N, Charkhat Gorgich E, Rezvani Amin M, Shahrakipoor M. Occupational stress in operating room and anesthesia technicians of Zahedan Ali ebne Abitaleb hospital. Journal of Student Research Center (Beyhagh) 2015; 20(2):33-41.
13. Asadi Fakhr A, Asadi S. Investigation of the amount of stressors in operating room nurses. Pajouhan Scientific Journal 2017; 15(2):27-31.

14. Chen CK, Lin C, Wang SH, Hou TH. A study of job stress, stress coping strategies, and job satisfaction for nurses working in middle-level hospital operating rooms. J Nurs Res 2009; 17(3):199-211.

15. Folkman S. Stress: appraisal and coping. In: Gellman MD, Turner JR, editors. Encyclopedia of behavioral medicine. New York (NY): Springer; 2013. P.1913-5.

16. Hinds PS, Srivastava DK, Randall EA, Green A, Stanford D, Pinlac R, et al. Testing the revised stress-response sequence model in pediatric oncology nurses. J Pediatr Oncol Nurs 2003; 20(5):213-32.

17. Charnley E. Occupational stress in the newly qualified staff nurse. Nurs Stand 1999; 13(29):33-6.

18. Tylor CR, Lillis C, LeMone P, Lynn P. Fundamentals of nursing: the art of science and nursing care. $7^{\text {th }}$ ed. Philadelphia, United States: Lippincott Williams and Wilkins; 2010.

19. Glazer Sh, Gyurak A. Sources of occupational stress among nurses in five countries. Int $\mathbf{J}$ Intercult Relat 2008; 32(1):49-66.

20. Kolakari Sh, Sanakoo A, Mirkarimei F, Behnampour N. The level of stress among Gorgan University of Medical Sciences hospital operation room's personals and its relation to some related factors. Journal of Gorgan University of Medical Sciences 2002; 4(2):54-9.

21. French SE, Lenton R, Walters V, Eyles J. An empirical evaluation of an expanded nursing stress scale. J Nurs Meas 2000; 8(2):161-78.

22. AbuRuz ME. A comparative study about the impact of stress on job satisfaction between jordanian and saudi nurses. Eur Sci J 2014; 10(17):162-72.

23. Ghanei Gheshlagh R, Valiei S, Rezaei M, Rezaei K. The relationship between personality characteristics and nursing occupational stress. Iranian Journal of Psychiatric Nursing 2013; 1(3):27-34.

24. Milutinović D, Golubović B, Brkić N, Prokeš B. Professional stress and health among critical care nurses in Serbia. Arh Hig Rada Toksikol 2012; 63(2):171-80

25. Esfandnia A, Nasiri E, khezli M, Esfandnia F, Bayat R. Job stress in nurses of teaching hospital of Imam Reza Kermanshah, 2015. Acta Medica Mediterranea 2016; 32:983-6.

26. Adeb-Saeedi J. Stress amongst emergency nurses. Australas Emerg Nurs J 2002; 5(2):1924. 
27. Ghasemi SA, Attar M. Investigate of intensity of job stressors of nurses in the hospitals Babol, Sari and Behshahr [Internet]. 2008 [cited 2008 July 12]. Avaiable from: http://www.betsaonline.com/ergonomy/faEster esShoghli.pdf

28. EL-Desouky AR, EL-Wazery MS. Mixed mode crack propagation of zirconia/nickel functionally graded materials. International Journal of Engineering 2013; 26(8):885-94.

29. Hopkinson JB, Hallett CE, Luker KA. Caring for dying people in hospital. J Adv Nurs 2003; 44(5):525-33.

30. Karimi Moneghy H, Zubin F, Yavari M, Noghredani M, Abdollahi H. Nurses' experience of dealing with dying patients. Journal of Urmia Nursing and Midwifery Faculty 2013; 11(9):688-97.

31. Hebrani P, Behdani F, Mobtaker M. Evaluation of stress factors in nurses of different hospital wards. Journal of fundamentals of Mental Health 2008; 10(39):231-7.

32. Mays RJ. Can compassionate care be documented in the electronic medical record? Pomona, CA, United States: Western University of Health Sciences, ProQuest Dissertations Publishing; 2012.

33. Crigger NJ, Brannigan $M$, Baird $M$. Compassionate nursing professionals as good citizens of the world. ANS Adv Nurs Sci 2006; 29(1):15-26.
34. Fowler MDM. Guide to the code of ethics for nurses: Interpretation and application. Silver Spring, Maryland, United States of America: American Nurses Association, Nursesbooks; 2008.

35. Hinkle JL, Cheever KH. Brunner \& Suddarth's textbook of medicaln - surgical nursing. $13^{\text {th }}$ ed. Philadelphia, United States: Lippincott Williams and Wilkins; 2010.

36. Abou Hashish EA. Relationship between ethical work climate and nurses' perception of organizational support, commitment, job satisfaction and turnover intent. Nurs Ethics 2017; 24(2):151-66.

37. Payne SA, Dean SJ, Kalus C. A comparative study of death anxiety in hospice and emergency nurses. J Adv Nurs 1998; 28(4):700-6.

38. Mohebbifar R, Kiaei MZ, Khosravizadeh O, Sadeghi T, Ahansazan H. Job stress and its related factors in nurses of Qazvin University of Medical Sciences. Journal of Medical Education and Development 2015; 7(1):55-63.

39. Hazavehei MM, Hosseini Z, Moeini B, Moghimbeigi A, Hamidi Y. Assessing stress level and stress management among Hamadan hospital nurses based on precede model. Quarterly of Horizon of Medical Sciences 2012; 18(2):78-85. 